\section{FUTEBOL DE MULHERES LIDERADO POR HOMENS: UMA ANÁLISE LONGITUDINAL DOS CARGOS DE COMISSÃO TÉCNICA E ARBITRAGEM}

\author{
MALE LEADERSHIP IN WOMEN'S FOOTBALL: A LONGITUDINAL \\ ANALYSIS OF COACHING AND REFEREE POSITIONS C \\ FÚTBOL FEMENINO LIDERADO POR HOMBRES: UN ANÁLISIS \\ LONGITUDINAL DE LOS CARGOS DE COMISIÓN TÉCNICA Y \\ ARBITRAJEC P
}

doi' https://doi.org/10.22456/1982-8918.100575

Julia Gravena Passero*<juliapassero@gmail.com>

Júlia Barreira* <jubarreira2@hotmail.com>

Lucas Tamashiro*<lucastamashiro7@gmail.com>

Alcides José Scaglia** <alcides.scaglia@gmail.com>

Larissa Rafaela Galatti** <lagalatti@hotmail.com>

*Universidade Estadual de Campinas. Campinas, SP, Brasil.

${ }^{* *}$ Universidade Estadual de Campinas. Limeira, SP, Brasil.

Resumo: O objetivo deste estudo foi analisar a participação das mulheres nos cargos de comissão técnica e de arbitragem no Campeonato Brasileiro de Futebol Feminino desde a primeira edição da competição, em 2013, até o ano de 2019. Analisamos a quantidade de mulheres atuantes como treinadoras, auxiliares técnicas, preparadoras físicas, massagistas, treinadoras de goleiras, fisioterapeutas e médicas. Também coletamos informações sobre o quarteto de arbitragem. Verificamos um predomínio ( $86 \%)$ de homens em cargos de comissão técnica com um lento aumento da participação de mulheres. As mulheres parecem ter maior inserção nos cargos de comissão de arbitragem. Encontramos 39\% de mulheres atuando como árbitras principais e $59 \%$ como árbitras assistentes. Verificamos que a participação de mulheres nos cargos de comissão técnica e de arbitragem no Campeonato Brasileiro de Futebol Feminino aumentou vagarosamente nos últimos anos, mas que a situação permanece de desigualdade.

Palavras chave: Comitê de profissionais. Igualdade de Gênero. Futebol.
Recebido em: 19-02-2020 Aprovado em: 29-06-2020 Publicado em: 15-08-2020

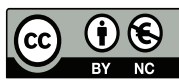

Este é um artigo publicado sob a licença Creative Commons atribuição Não Comercial 4.0 (CC BY-NC 4.0).

elSSN: $1982-8918$ 


\section{INTRODUÇÃO}

A literatura internacional explora há décadas as dificuldades enfrentadas por mulheres em posições de liderança no esporte (BURTON, 2015; SARTORE; CUNNIGHAM, 2007). A construção do papel social da mulher ao longo do século XX limitou o acesso das praticantes em determinadas modalidades esportivas e praticamente impossibilitou a entrada e a ascensão dessas profissionais em cargos de liderança (PFISTER, 2010). O futebol foi uma das modalidades mais vinculadas aos atributos da masculinidade e que, consequentemente, apresentou grande resistência social para a participação de meninas e mulheres. As barreiras sociais foram enfrentadas em diversos países do mundo (HONG; MANGAN, 2003), e o caso brasileiro apresentou uma particularidade pois, além da generificação do esporte, a proibição legal decretada em 1965 também impediu que as mulheres praticassem a modalidade por décadas no país (BRASIL, 1965). A proibição não foi suficiente para impedir que elas se organizassem em campos de várzea e nas periferias, mas impossibilitou o processo de formação das praticantes e a qualificação das profissionais (SILVA, 2017).

Diversos estudos nacionais exploraram os desafios enfrentados na prática do futebol de mulheres durante o último século (BARREIRA, 2018). Ao analisar o preconceito de gênero a partir de uma revisão sistemática, Teixeira e Caminha (2013) mostraram que meninas e mulheres enfrentam dificuldades em relação à segregação, à exclusão, ao cerceamento da mulher em determinadas práticas esportivas, à erotização dos corpos e à vigilância sobre a identidade de gênero. Já as investigações sobre as trajetórias de mulheres que atuam como líderes no futebol brasileiro são mais recentes e ainda escassas (CALHEIRO, 2018; NOVAIS, 2017; 2018; WOLF, 2017).

Ao analisar as experiências de mulheres que atuam como treinadoras e auxiliares no Campeonato Brasileiro de Futebol Feminino e na Copa do Brasil, Novais (2018) identificou que a carreira das profissionais é marcada pela transposição de barreiras e superação de desafios desde que eram jogadoras até se tornarem treinadoras. As participantes do estudo se mostram otimistas em relação às possibilidades de ascensão na modalidade em função das novas regras impostas pelas federações responsáveis pela organização do futebol no Brasil e na América do Sul. De acordo com o novo licenciamento da Confederação Brasileira de Futebol (CBF), os clubes que não tiverem um time de mulheres disputando campeonatos oficiais não poderão participar de competições internacionais de futebol de homens. As estrevistadas relataram a expectativa de melhores estruturas para as equipes que disputam as competições nacionais de futebol de mulheres, além de um maior incentivo à participação das profissionais e das atletas na modalidade (NOVAIS, 2018).

O otimismo apontado pelas treinadoras e auxiliares se deu em um cenário anterior à vigência da obrigatoriedade. A nova regra de licenciamento entrou em vigor no ano de 2019 e desconhecemos estudos nacionais que tenham investigado as transformações no futebol de mulheres de alto rendimento nesse espaço de 
tempo. Apesar das perspectivas apresentadas pelas profissionais nesse período de transição, a experiência com uma política esportiva similar proposta no território norte-americano é alarmante. A Title IX, lei americana criada em 1972, exigiu que todo investimento realizado no esporte pelo sistema educacional do país fosse igual para homens e mulheres. Apesar do aumento no número de praticantes e do sucesso atual dos Estados Unidos em competições de mulheres, estudos mostraram que o número de treinadoras reduziu de $90 \%$ para $43 \%$ após 35 anos de implementação da lei (ACOSTA; CARPENTER, 2012).

Para as estudiosas da área, à medida que os esportes praticados por mulheres ganharam visibilidade nos Estados Unidos, homens passaram a demonstrar um maior interesse em desenvolver carreiras nessas modalidades (ACOSTA; CARPENTER, 2012). É possível que, com a exigência da CBF, o mesmo efeito rebote aconteça com as profissionais que atuam no futebol brasileiro de elite praticado por mulheres. Para analisar as implicações da nova regra nos cargos de liderança, é necessário conhecer o cenário atual das treinadoras brasileiras. Os poucos estudos existentes sobre a participação da mulher em posições de visibilidade no futebol brasileiro investigaram as trajetórias das treinadoras, auxiliares técnicas e árbitras (CALHEIRO, 2018; NOVAIS, 2017; 2018; WOLF, 2017). Ainda é desconhecida a participação das profissionais em outros cargos de comissão técnica e de arbitragem. Portanto, o objetivo deste estudo foi analisar longitudinalmente a participação de mulheres em cargos de comissão técnica e arbitragem no Campeonato Brasileiro de Futebol Feminino (2013-2019). Optamos por analisar o Campeonato Brasileiro por ser a principal competição nacional de futebol do país. Focamos na prática por mulheres, primeiro por ser a categoria afetada pela exigência da confederação, e segundo pela ausência dessas profissionais nas comissões técnicas e de arbitragem no futebol de espetáculo praticado por homens (DAMO, 2005). Por fim, escolhemos a análise longitudinal, desde a primeira edição do campeonato até o presente momento, com o intuito de fornecer dados retrospectivos sobre a participação das mulheres nos cargos de liderança e promover a discussão sobre a inserção da mulher em posições de visibilidade no esporte ao longo dos anos. Além do debate acadêmico proporcionado por este estudo, os dados aqui fornecidos podem ser utilizados como fonte histórica para a análise das consequências do decreto da CBF nos próximos anos.

\section{REVISÃO DE LITERATURA}

A literatura sugere que as mulheres ainda são marginalizadas, discriminadas e desvalorizadas em posições de liderança no esporte (KANE; STANGL, 1991; NORMAN, 2010b; SARTORE; CUNNINGHAM, 2007). Entre essas posições podemos citar os cargos de comissão técnica, arbitragem e de gestão. As profissionais enfrentam desafios tanto no processo de inserção quanto na manutenção e progressão da carreira. Eagly e Carli (2007) sugerem que, apesar do estilo de liderança depender do contexto em que o líder se encontra, historicamente a liderança é definida em termos masculinos. Os atributos tradicionalmente masculinos são esperados e supervalorizados nesses cargos e as características de feminilidade, tradicionalmente vinculadas à mulher, são indesejadas nesse contexto. Para serem competitivas em 
posições de poder, mulheres frequentemente se submetem a um extenso processo de qualificação que nem sempre é exigido dos homens. Uma vez que alcançam os cargos de visibilidade, são constantemente desafiadas em relação à sua capacidade de liderar.

Os cargos de liderança no esporte comumente são associados à estrutura de poder na sociedade e reproduzem a hierarquia de gênero. Goellner (2007) reforça a importância da utilização do "gênero" como uma categoria analítica para compreender os processos pelos quais, no interior de redes de poder, a diferença biológica é tomada para explicar desigualdades sociais, perpetuando formas de inclusão e exclusão de sujeitos e grupos. Nessa relação de poder, atitudes negativas e depreciativas são expressas e desenvolvidas, além de comportamentos hostis por parte de um grupo em relação a membros de outro grupo, geralmente possuidor de menor status ou prestígio (FERREIRA et al., 2017). Nesse sentido, as estruturas instituicionais tidas como inapropriadas às mulheres não propiciam o seu sucesso profissional e, consequentemente, impedem a sua chegada nas áreas de maior prestígio (SOARES, 2001).

As barreiras sociais enfrentadas e a sub-representação das mulheres no cargo de treinadora foram bastante exploradas pela literatura científica (WALKER; BOPP, 2011). Estudos mostraram que, apesar das mulheres ganharem espaço como treinadoras esportivas ao longo dos anos, esse cargo ainda é majoritariamente ocupado por homens, sendo essa diferença cada vez maior à medida que nos aproximamos do alto rendimento esportivo (PFISTER, 2010). Por exemplo, as mulheres representam $20 \%$ das treinadoras no sistema universitário canadense (READE; RODGERS; NORMAN, 2009). No Brasil, essa participação diminui para 7\% como treinadoras de equipes de mulheres que disputam campeonatos nacionais (FERREIRA; SALLES; MOURÃO; MORENO, 2013). Por fim, no Reino Unido, a representatividade de mulheres treinadoras nas seleções é de apenas 4\% (NORMAN, 2010). Apesar dos países apresentarem características culturais distintas e, consequentemente, diferentes concepções sobre o papel da mulher na sociedade, os estudos revelam as dificuldades enfrentadas por treinadoras de diferentes nacionalidades principalmente em relação à progressão de carreira. De acordo com Hargreaves (1994), o cargo de treinador/treinadora é uma das áreas do esporte em que há um desequilíbrio significativo de gênero devido à sua visibilidade e ao seu protagonismo.

Os poucos estudos no cenário brasileiro corroboram as dificuldades apresentadas acima. Novais (2018) investigou as trajetórias e experiências de treinadoras e auxiliares técnicas que disputaram o Campeonato Brasileiro de Futebol Feminino e a Copa do Brasil em 2016. A autora encontrou um processo de inserção, permanência e ascensão profissional marcado pela transposição de barreiras e superação de desafios. Além disso, as mulheres apresentaram um alto grau de capacitação e um bom desempenho quando atletas, reforçando a necessidade de qualificação para se inserirem e permanecerem nos cargos (NOVAIS, 2018). O mesmo cenário de dificuldades foi encontrado no trabalho realizado por Wolf (2017) ao analisar entrevistas e depoimentos de ex-atletas que se tornaram treinadoras de futebol de elite. As treinadoras relataram a necessidade de qualificação e as dificuldades em relação aos salários e ao reconhecimento social. 
Ao contrário da vasta literatura internacional produzida sobre mulheres treinadoras, poucos estudos investigaram as questões de gênero em outros cargos de comissão técnica. As investigações sobre o tema se debruçaram sobre a participação das assistentes técnicas em competições nacionais de basquetebol praticado por mulheres nos Estados Unidos (WALKER; BOPP, 2010) e no Brasil (PASSERO et al., 2019). Ambos os estudos encontraram uma maior participação de mulheres como assistentes do que como treinadoras. Esses achados reforçam a dificuldade de progressão das mulheres aos cargos de maior visibilidade. Além das barreiras sociais encontradas para inserção em equipes de alto rendimento, a visibilidade também limita a participação das mulheres a posições de menor protagonismo dentro das equipes esportivas. É possível que resultados parecidos sejam encontrados no futebol brasileiro de elite praticado por mulheres, e que esse padrão também se manifeste em outros cargos de comissão técnica, como de preparadora física, treinadora de goleiras e fisiologista.

As mulheres que atuam como árbitras também são frequentemente questionadas, com base nos estereótipos de gênero, sobre a sua competência antes mesmo de entrarem em campo (FORBES; EDWARDS; FLEMING, 2015). A associação entre autoridade e masculinidade é uma das possíveis explicações para os desafios sociais enfrentados pelas profissionais (NORMAN, 2010b). Os frequentes questionamentos em relação às suas competências fazem com que as árbitras se coloquem em constante pressão para tomarem decisões certas e não abrirem espaço para discussão sobre a capacidade de mulheres arbitrarem (FORBES et al., 2015). A luta dessas profissionais é tão marcante que os poucos registros de árbitras que atuaram no futebol brasileiro ao longo do século XX marcaram a história.

No Brasil, Léa Campos enfrentou grandes dificuldades para se tornar árbitra de futebol na década de 1970. Com o objetivo de se qualificar, Lea realizou oito meses de curso de arbitragem em 1967 na Federação Mineira de Futebol. Entretanto, seu diploma foi reconhecido pela Fédération Internationale de Football Association (FIFA) somente quatro anos depois (SCHUMAHER, 2000). Além da pioneira Léa Campos, outras personagens nacionais também foram marcantes na luta pela participação das mulheres como árbitras. Podemos citar Cláudia de Vasconcellos Guedes, primeira mulher a arbitrar uma competição oficial organizada pela FIFA, atuando na estreia da Copa do Mundo de Futebol Feminino em 1991 (MONTEIRO, 2016). Silvia Regina de Oliveira também teve um papel importante ao se tornar a primeira mulher a arbitrar uma partida da Copa Sul-Americana de homens em 2003, e Ana Paula Oliveira ao atuar como a primeira assistente em uma partida da Copa Libertadores da América de homens em 2005 (MONTEIRO, 2016).

Além das personagens marcantes na história da arbitragem, estudos nacionais também investigaram quantitativamente a participação das mulheres como árbitras. Calheiro (2017) encontrou que as mulheres correspondiam a 15\% e 13\% na relação de árbitros da CBF nos anos de 2012 e 2014. Achados semelhantes foram encontrados por Monteiro, Soares e Mourão (2015) ao mostrarem uma sub-representação de mulheres (15\%) como árbitras, assistentes e bandeirinhas no quadro da CBF em 2014. De acordo com Calheiro (2017), esse número é crescente nas últimas décadas, 
entretanto a magnitude desse crescimento ainda é desconhecida no Campeonato Brasileiro de Futebol Feminino, assim como as diferenças apresentadas pelos diferentes cargos de comissão de arbitragem.

\section{MÉTODO}

Neste estudo analisamos a participação de mulheres nos cargos de comissão técnica e arbitragem em sete edições do principal campeonato nacional de futebol de mulheres, o Campeonato Brasileiro de Futebol Feminino. As súmulas oficiais da competição, disponíveis no site da CBF, foram utilizadas para a coleta dos dados. Devido à alternan̂cia dos membros de comissão técnica ao longo do Campeonato, analisamos todos os jogos das edições de 2013 a 2019. O Campeonato Brasileiro de Futebol Feminino foi criado em 2013, ano utilizado com limite inferior para a nossa coleta de dados. A partir do ano de 2017 foi criada a série A2 do campeonato, incluída na coleta de dados. Todos os dados foram coletados em novembro de 2019, ano utilizado como limite superior para a análise.

A Tabela 1 apresenta a quantidade de jogos sem súmula ao longo de todas as edições e que, portanto, não foram analisados no trabalho. Da mesma forma, são apresentadas todas as súmulas disponíveis e utilizadas no estudo.

Tabela 1 - Quantidade de jogos sem súmula ao longo de todas as edições do Campeonato Brasileiro de Futebol Feminino (2013-2019).

\begin{tabular}{lcccccccccc}
\hline Edições & $\mathbf{2 0 1 3}$ & $\mathbf{2 0 1 4}$ & $\mathbf{2 0 1 5}$ & $\mathbf{2 0 1 6}$ & $\begin{array}{c}\mathbf{2 0 1 7} \\
\mathbf{A 1}\end{array}$ & $\begin{array}{c}\mathbf{2 0 1 7} \\
\mathbf{A 2}\end{array}$ & $\begin{array}{c}\mathbf{2 0 1 8} \\
\mathbf{A 1}\end{array}$ & $\begin{array}{c}\mathbf{2 0 1 8} \\
\mathbf{A 2}\end{array}$ & $\begin{array}{c}\mathbf{2 0 1 9} \\
\text { A1 }\end{array}$ & $\begin{array}{c}\mathbf{2 0 1 9} \\
\text { A2 }\end{array}$ \\
\hline Equipes & 20 & 20 & 20 & 20 & 16 & 16 & 16 & 29 & 16 & 36 \\
& & & & & & & & & & \\
Jogos sem & 3 & 0 & 0 & 1 & 0 & 1 & 0 & 0 & 0 & 0 \\
súmula & $(4 \%)$ & $(0 \%)$ & $(0 \%)$ & $(1 \%)$ & $(0 \%)$ & $(2 \%)$ & $(0 \%)$ & $(0 \%)$ & $(0 \%)$ & $(0 \%)$ \\
Jogos com & 67 & 70 & 70 & 69 & 126 & 61 & 126 & 75 & 134 & 120 \\
súmula & $(96 \%)$ & $(100 \%)$ & $(100 \%)$ & $(99 \%)$ & $(100 \%)$ & $(98 \%)$ & $(100 \%)$ & $(100 \%)$ & $(100 \%)$ & $(100 \%)$ \\
Total de & 70 & 70 & 70 & 70 & 126 & 62 & 126 & 75 & 134 & 120 \\
jogos & $(100 \%)$ & $(100 \%)$ & $(100 \%)$ & $(100 \%)$ & $(100 \%)$ & $(100 \%)$ & $(100 \%)$ & $(100 \%)$ & $(100 \%)$ & $(100 \%)$ \\
\hline
\end{tabular}

Fonte: Elaborado pelos autores

Coletamos os nomes dos profissionais que ocupavam os seguintes cargos da comissão técnica de ambos os times por partida: técnico, auxiliar técnico, preparador físico, massagista, treinador de goleiras, fisioterapeuta e médico. Também coletamos essa informação do quarteto de arbitragem. A partir dos nomes, os profissionais foram classificados entre homens ou mulheres. Para as classificações que geraram

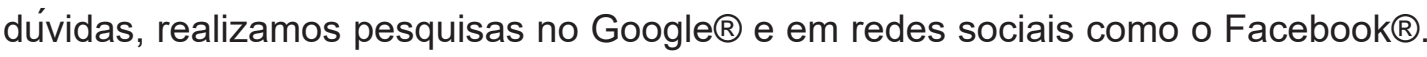
Em algumas súmulas encontramos nomes que ocupavam dois cargos de comissão técnica, considerados duplicados. Nesses casos, a mesma classificação foi utilizada para ambos cargos.

A Tabela 2 (na próxima página) apresenta os cargos das comissões técnicas cujas informações constam nas súmulas disponíveis online e que foram utilizados 
para a análise. A frequência relativa apresentada na Tabela 2 se refere à quantidade de jogos que apresentaram as informações preenchidas sobre o respectivo cargo de comissão técnica.

Tabela 2 - Cargos de comissão técnica que constam na súmula ao longo das edções do Campeonato Brasileiro de Futebol Feminino (2013-2019).

\begin{tabular}{|c|c|c|c|c|c|c|c|c|c|c|}
\hline Edições & 2013 & 2014 & 2015 & 2016 & $\begin{array}{c}2017 \\
\text { A1 }\end{array}$ & $\begin{array}{c}2017 \\
\text { A2 }\end{array}$ & $\begin{array}{c}2018 \\
\text { A1 }\end{array}$ & $\begin{array}{c}2018 \\
\text { A2 }\end{array}$ & $\begin{array}{c}2019 \\
\text { A1 }\end{array}$ & $\begin{array}{c}2019 \\
\text { A2 }\end{array}$ \\
\hline Técnico & $100 \%$ & $100 \%$ & $100 \%$ & $100 \%$ & $100 \%$ & $98 \%$ & $96 \%$ & $91 \%$ & $93 \%$ & $93 \%$ \\
\hline $\begin{array}{l}\text { Auxiliar } \\
\text { Técnico }\end{array}$ & $63 \%$ & $74 \%$ & $74 \%$ & $86 \%$ & $68 \%$ & $75 \%$ & $69 \%$ & $77 \%$ & $80 \%$ & $81 \%$ \\
\hline $\begin{array}{l}\text { Preparador } \\
\text { Físico }\end{array}$ & $90 \%$ & $92 \%$ & $79 \%$ & $80 \%$ & $92 \%$ & $73 \%$ & $90 \%$ & $65 \%$ & $93 \%$ & $83 \%$ \\
\hline Massagista & $94 \%$ & $86 \%$ & $91 \%$ & $90 \%$ & $96 \%$ & $87 \%$ & $88 \%$ & $67 \%$ & $74 \%$ & $74 \%$ \\
\hline $\begin{array}{l}\text { Treinador de } \\
\text { goleiro }\end{array}$ & $7 \%$ & $0 \%$ & $0 \%$ & $1 \%$ & $43 \%$ & $60 \%$ & $62 \%$ & $79 \%$ & $75 \%$ & $95 \%$ \\
\hline Médico & $51 \%$ & $44 \%$ & $54 \%$ & $65 \%$ & $68 \%$ & $53 \%$ & $55 \%$ & $57 \%$ & $56 \%$ & $91 \%$ \\
\hline Fisioterapeuta & $44 \%$ & $0 \%$ & $2 \%$ & $1 \%$ & $0 \%$ & $0 \%$ & $10 \%$ & $21 \%$ & $24 \%$ & $91 \%$ \\
\hline
\end{tabular}

Fonte: Elabadora pelos autores.

Todos os dados foram tabulados em planilha Microsoft Excel ${ }^{\circledR}$ e exportados para o MATLAB $2010 \AA$, software utilizado para as análises estatísticas. O coeficiente de correlação de Pearson foi usado para analisar a participação das mulheres nas posições de comissão técnicas ao longo dos anos. Os cargos de treinadora de goleira e fisioterapeuta não foram analisados longitudinalmente devido aos dados faltantes em algumas edições (Tabela 2). Dado o baixo número de edições analisadas neste estudo e a influência do tamanho da amostra na significância da análise de correlação, o coeficiente foi interpretado como uma pequena correlação $0,1<|r| \leq 0,3$; correlação média $0.3<|r| \leq 0,5$ e grande correlação $0,5<|r| \leq 1,0$ (COHEN, 1988). A regressão linear simples foi utilizada para estimar o ano em que a quantidade de mulheres $\mathrm{e}$ homens se igualaria em cada cargo analisado.

\section{RESULTADOS}

A Figura 1 apresenta a participação de homens e mulheres nos cargos de comissão técnica ao longo de todas as edições do campeonato. Verificamos uma predominância de homens em todas as posições analisadas. O cargo em que há uma maior participação de mulheres é o de auxiliar técnica, seguido por massagista e treinadora. 
Figura 1 - Distribuição de gênero por cargo da comissão técnica em todas as edições do Campeonato Brasileiro de Futebol Feminino (2013-2019).

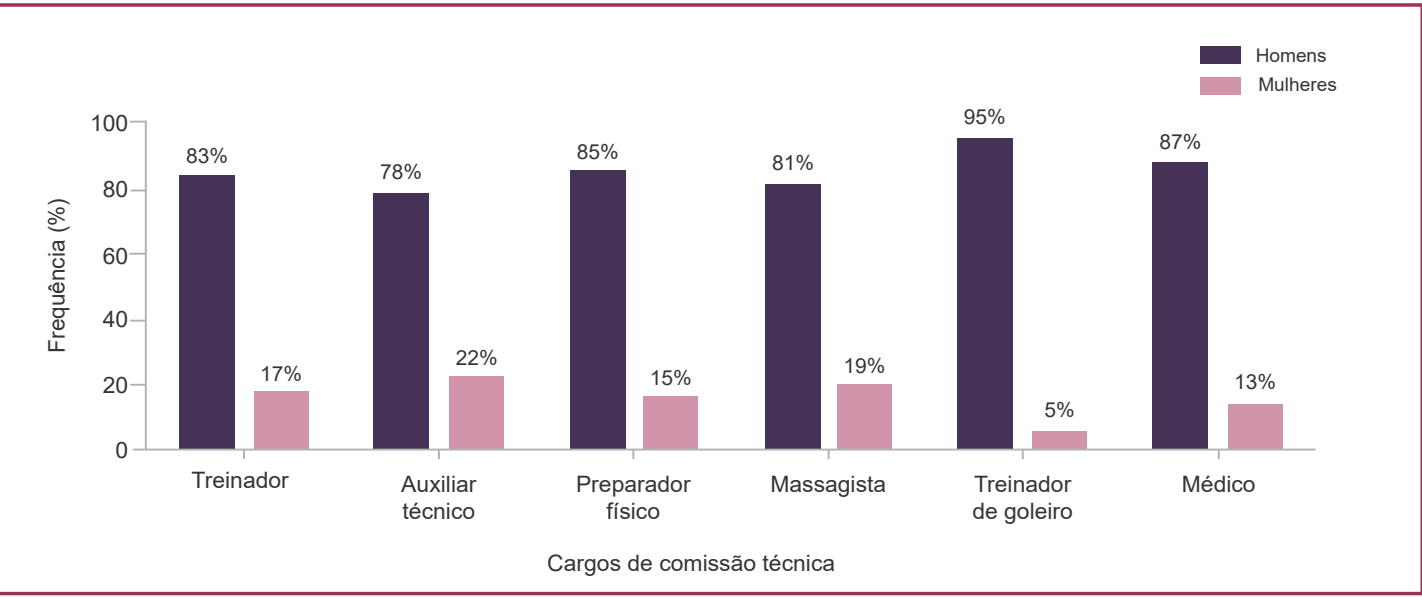

Fonte: Elaborada pelos autores

A Figura 2 apresenta o percentual das mulheres que atuaram em cargos de comissão técnica ao longo dos anos. Notamos um aumento lento e gradual na partição de mulheres em todos os cargos analisados.

Figura 2 - Frequência das mulheres em cargos da comissão técnica ao longo das edições do Campeonato Brasileiro de Futebol Feminino (2013-2019).
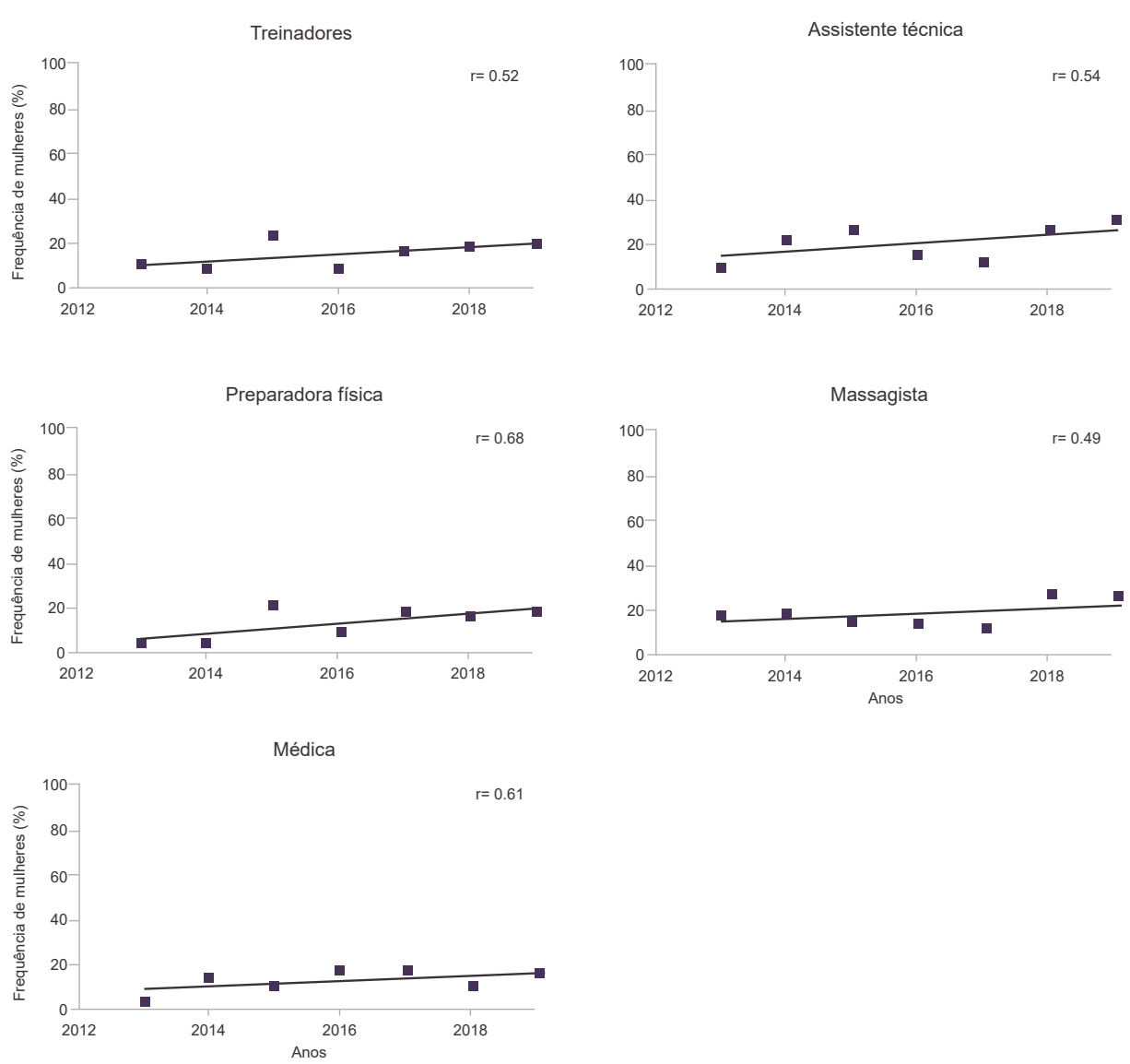

Fonte: Elaborada pelos autores 
Com base nas equações lineares apresentadas na Tabela 3, estimamos os anos em que as mulheres alcançariam a mesma proporção que os homens em cada cargo. Os resultados mostram que, se não houver rupturas e a participação das mulheres continuar aumentando linearmente ao longo do tempo, a igualdade numérica será alcançada entre as décadas de 2030 e 2040.

Tabela 3 - Regressão linear referente ao aumento das mulheres nos cargos de comissão técnica do Campeonato Brasileiro de Futebol Feminino (2013-2019)

\begin{tabular}{lcccc}
\hline Regressão Linear & $\begin{array}{c}\text { Coeficiente } \\
\text { angular }\end{array}$ & $\begin{array}{c}\text { Coeficiente } \\
\text { linear }\end{array}$ & $\mathbf{R}^{\mathbf{2}}$ & $\begin{array}{c}\text { Ano em que as mulheres } \\
\text { alcançarão 50\% }\end{array}$ \\
\hline Treinadoras & 1.43 & -2864 & $27 \%$ & 2038 \\
Auxiliar Técnica & 2.00 & -4011 & $29 \%$ & 2031 \\
Preparadora Física & 2.25 & -4523 & $47 \%$ & 2032 \\
Massagista & 1.32 & -2646 & $24 \%$ & 2042 \\
Médica & 1.39 & -2796 & $38 \%$ & 2047 \\
\hline
\end{tabular}

Fonte: Elaborada pelos autores

A Figura 3 apresenta a distribuição de homens e mulheres em cada cargo de arbitragem durante todos os anos analisados. Comparado aos cargos de comissão técnica, encontramos um maior equilíbrio entre homens e mulheres nos cargos de arbitragem. Os homens são mais frequentes nas posições de árbitro principal e quarto árbitro. Já as mulheres têm uma maior participação como árbitras assistentes.

Figura 3 - Participação de homens e mulheres em cargos da comissão de arbitragem em todas as edições do Campeonato Brasileiro de Futebol Feminino (2013-2019).

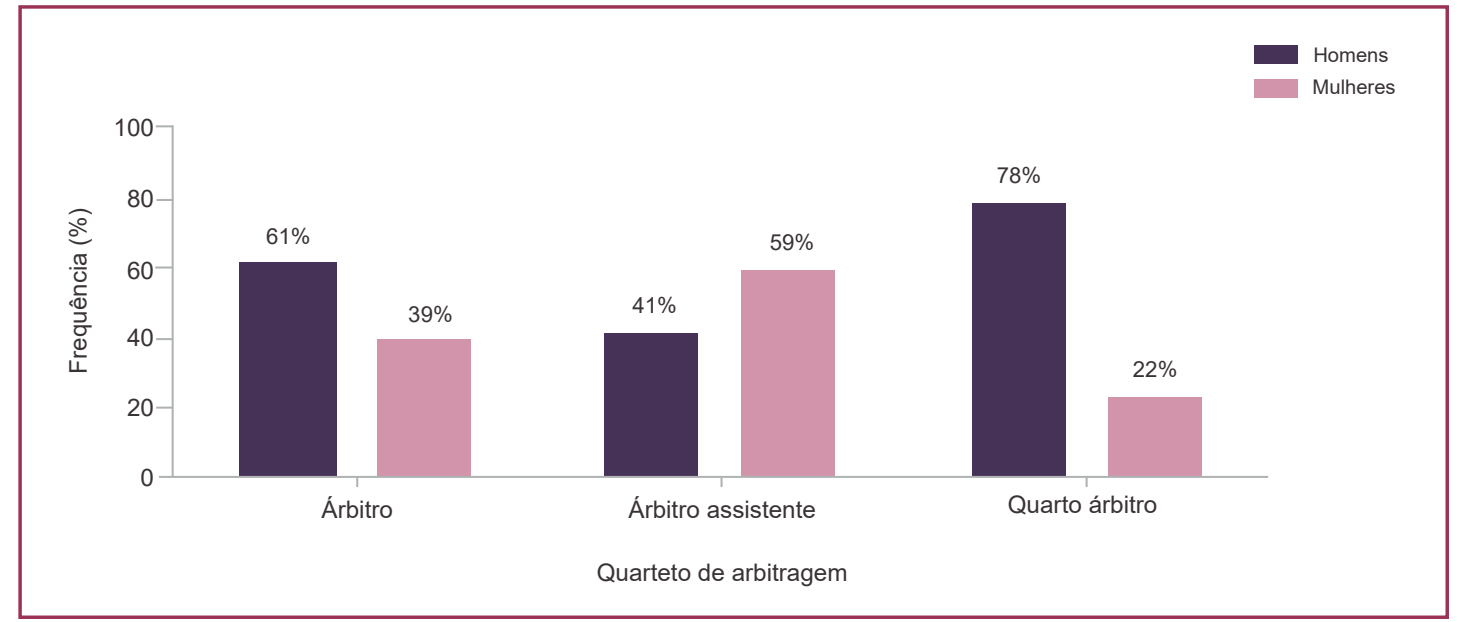

Fonte: Elaborada pelos autores

A Figura 4 apresenta o percentual das mulheres em cargos de comissão de arbitragem ao longo das edições. Vemos uma relativa estabilização nos cargos de árbitra e árbitra assistente. Chama a atenção o fato de a participação das mulheres no cargo de quarta árbitra apresentar uma diminuição ao longo das edições. 
Figura 4 - Frequência das mulheres em cargos da comissão de arbitragem ao longo das seis edições do Campeonato Brasileiro de Futebol Feminino (2013-2019).

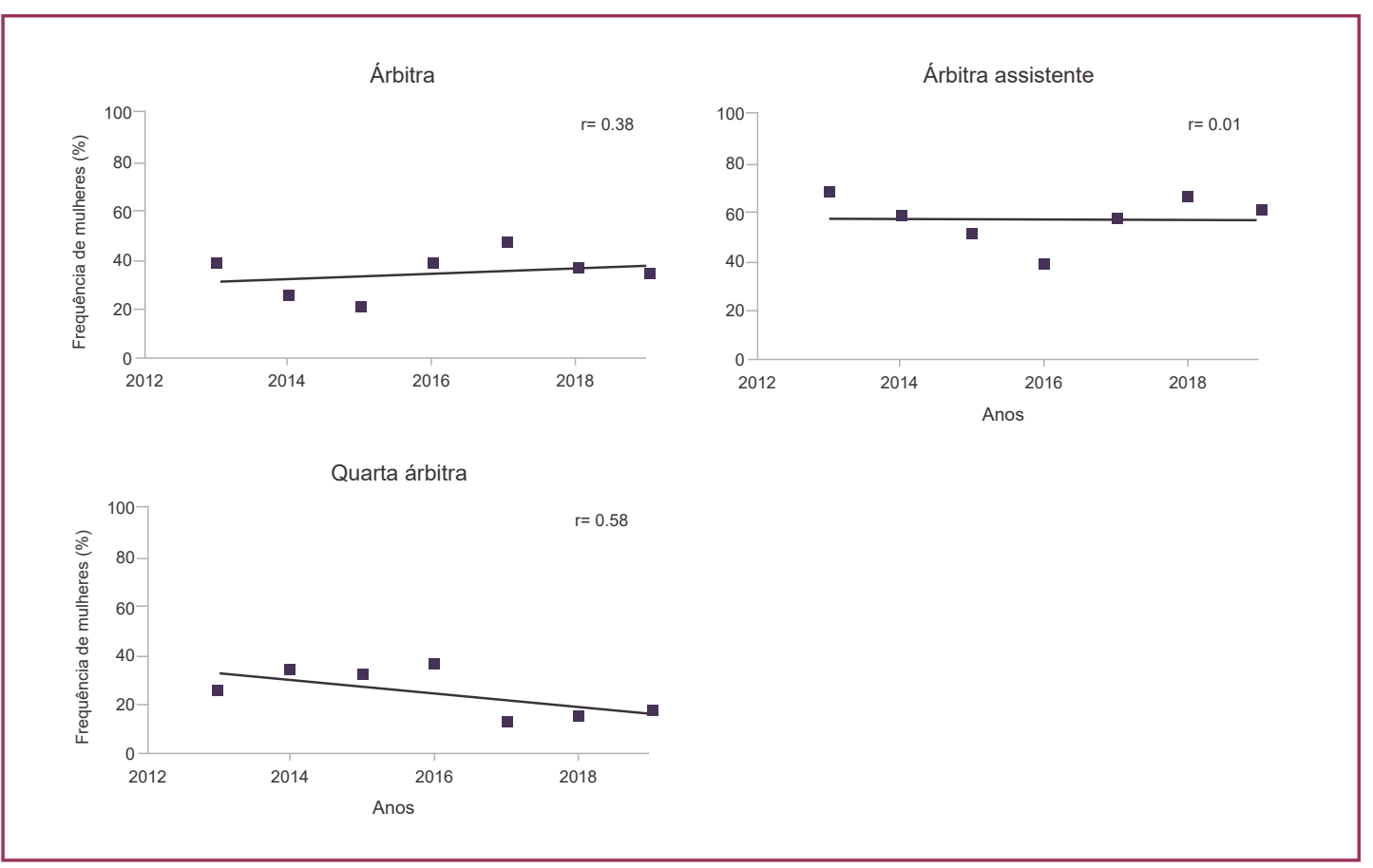

Fonte: Elaborada pelos autores

A Tabela 4 apresenta as estatísticas da regressão linear utilizada para estimar os anos em que as mulheres alcançariam a mesma proporção que os homens em cada cargo de comissão de arbitragem. Os resultados mostram que a proporção de mulheres atuando como árbitras vem aumentando lentamente nos últimos anos e que, se não houver rupturas, a igualdade numérica será alcançada em 2036. Já em relação à posição de árbitra assistente, encontramos uma estabilização na proporção de mulheres ao longo dos anos, portanto a análise de regressão linear apresenta um baixo poder explicativo $\left(\mathrm{R}^{2}<1 \%\right)$. Notamos uma diminuição da participação das mulheres como quarta árbitra ao longo dos anos, mostrando que a igualdade numérica em relação aos homens foi alcançada em 2008.

Tabela 4 - Regressão linear referente ao aumento das mulheres nos cargos de comissão de arbitragem do Campeonato Brasileiro de Futebol Feminino (2013-2019).

\begin{tabular}{lcccc}
\hline Regressão Linear & $\begin{array}{c}\text { Coeficiente } \\
\text { angular }\end{array}$ & $\begin{array}{c}\text { Coeficiente } \\
\text { linear }\end{array}$ & $\mathbf{R}^{\mathbf{2}}$ & $\begin{array}{c}\text { Ano em que as mulheres } \\
\text { alcançarão 50\% }\end{array}$ \\
\hline Árbitra & 1.28 & -2557 & $10 \%$ & 2036 \\
Árbitra Assistente & -0.07 & 201 & $0 \%$ & 2157 \\
Quarta árbitra & -2.82 & 5713 & $41 \%$ & 2008 \\
\hline
\end{tabular}

Fonte: Elaborada pelos autores

\section{DISCUSSÃO}

Neste estudo, investigamos a participação de mulheres em cargos de comissão técnica e como integrantes da equipe de arbitragem no Campeonato Brasileiro de Futebol Feminino de 2013 a 2019. Embora o período de sete anos seja um curto 
espaço de tempo para encontrar mudanças significativas no local de trabalho esportivo dominado pelos homens, os resultados permitem uma análise crítica da participação de mulheres no contexto do futebol de elite praticado por mulheres no Brasil. Verificamos um predomínio de homens em todos os cargos de comissão técnica com um lento aumento da participação das mulheres. As profissionais parecem ter maior inserção nos cargos de comissão de arbitragem devido à maior participação de mulheres como árbitras e assistentes. Os dados quantitativos apresentados neste estudo permitem acompanhar o processo de inserção de mulheres brasileiras em posições de liderança no esporte. Entretanto, essa análise pode e deve ser complementada por estudos qualitativos que investiguem os diferentes fatores que puderam contribuir para essa ocupação de mulheres em uma área tradicionalmente dominada por homens, assim como os constrangimentos enfrentados ao longo desse processo.

A quantidade de meninas e mulheres que praticam futebol no cenário brasileiro é crescente ao longo dos últimos anos (GOELLNER, 2005) e os resultados deste estudo apresentaram um aumento lento e gradual de mulheres em cargos de comissão técnica no Campeonato Brasileiro de Futebol Feminino. Entretanto, os cargos ainda são majoritariamente ocupados por homens, que representam mais de $80 \%$ desses profissionais. De todos os cargos no esporte, o de treinador captura elementos centrais na visão estereotipada do esporte como masculino (THEBERGE, 1993). Verificamos que as mulheres correspondem a $17 \%$ das treinadoras no Campeonato Brasileiro de Futebol Feminino e $24 \%$ na Liga Brasileira de Basquetebol (PASSERO et al., 2018). O Brasil apresenta um cenário semelhante a diversos países europeus, nos quais a proporção de mulheres treinadoras varia de $13 \%$ a 17\%, e que diminui à medida que se aproxima do alto rendimento esportivo (FASTING; SAND; NORDSTRAND, 2019). Diversos fatores podem explicar essa baixa representatividade de mulheres como treinadoras. As treinadoras brasileiras relataram que a falta de reconhecimento e os baixos rendimentos financeiros enfrentados no campo esportivo levaram as profissionais a buscarem outros empregos (FERREIRA et al., 2013). Há uma década, Romariz (2008) também apontava a inexistência de incentivos por meio de políticas para promoção de uma maior inserção de mulheres nos cargos de comando esportivo. Nos últimos anos o cenário brasileiro apresentou um aumento no número de políticas esportivas, mas faltam levantamentos e pesquisas que avaliem sua eficácia.

Outro fator que pode explicar a baixa participação de mulheres como treinadoras é o princípio de contratação por similaridade (KILTY, 2006). De acordo com Kanter (1993), no momento de contratação existe uma tendência para a aplicação do princípio de similaridade denominado de "reprodução homóloga". Dirigentes e treinadores perpetuam o predomínio dos homens ao contratarem apenas similares a eles mesmos; ou seja: homens tendem a optar por homens. Atualmente, as mulheres representam aproximadamente $8 \%$ das diretorias das federações de futebol em todo o Brasil (GOMES, 2012). Essa baixa representatividade por ser extrapolada para as posições de presidenta e coordenadora dos clubes de futebol brasileiro. Recentemente, Torga (2019) analisou a presença de mulheres em cargos de diretoria ou gestão em 60 clubes de futebol das séries A, B e C. A autora revelou uma subrepresentatividade das mulheres ao encontrar apenas cinco gestoras no contexto 
analisado. Portanto, a maior prevalência de homens nas posições de contratação nos clubes pode levar a uma maior contratação de treinadores homens para o futebol brasileiro, reforçando o ciclo vicioso.

Um cenário diferente foi encontrado no estudo de Novais (2018). Ao entrevistar treinadoras e auxiliares técnicas que atuam no Campeonato Brasileiro de Futebol Feminino e na Copa do Brasil, a autora observou que algumas profissionais foram indicadas e/ou contratadas por homens. De acordo com Novais (2018), alguns dirigentes brasileiros contrariam o princípio da similaridade ao se basearem nas capacidades intelectuais para contratarem os profissionais para os cargos de liderança e não se restringirem à contratação de homens.

Além de investigar a participação das treinadoras no Campeonato Brasileiro de Futebol Feminino, este estudo também avança com o conhecimento ao analisar a presença das mulheres em outros cargos de comissão técnica. Os resultados revelam que mulheres enfrentam barreiras mesmo nos cargos de liderança de menor visibilidade, correspondendo a apenas 15\% desses profissionais. Os dados quantitativos revelam que as barreiras sociais ainda limitam a inserção das mulheres em todas as posições de liderança no esporte. Encontramos o aumento lento e gradual da participação de mulheres em cargos de comissão técnica, com possibilidade de alcançar a igualdade numérica com os homens entre 2030 e 2040. As organizações esportivas e instituições de ensino brasileiras têm um papel importante em acelerar esse processo ao capacitarem mulheres para trabalharem com o esporte.

Um outro resultado inovador encontrado no nosso estudo e que permite novas percepções é a maior inserção das mulheres na equipe de arbitragem comparada aos cargos de comissão técnica. A maior atuação das mulheres não acontece necessariamente sem desafios, mas revela a possibilidade de inserção principalmente nas posições de árbitras assistentes. Chama a atenção o fato da função de árbitro principal ainda ser predominantemente ocupada por homens, reforçando novamente a dificuldade de as profissionais progredirem para cargos de maior visibilidade. A progressão não é limitada necessariamente pela falta de habilidade e capacidade das mulheres, mas, sim, pelas barreiras estruturais da sociedade e do esporte. Por um lado, o cenário atual revela que o esporte, de maneira geral, reforça as desigualdades culturais entre os gêneros ao reproduzir as representações sociais em relação aos papéis desempenhados por homens e mulheres (GOELLNER, 2005). Por outro lado, a crescente quantidade de mulheres atuando como árbitras principais revela uma possibilidade de romper com as representações socialmente e historicamente estabelecidas.

Embora nossa investigação tenha adicionado percepções interessantes em relação à participação das mulheres que atuam em comissões técnicas e de arbitragem no Campeonato Brasileiro de Futebol Feminino, é importante reconhecer as limitações deste estudo. A primeira limitação está no método usado na coleta de dados. Mesmo que os dados quantitativos forneçam uma visão geral e valiosa, informações qualitativas são necessárias para fornecer uma melhor compreensão sobre esse complexo fenômeno. Em segundo lugar, o aumento quantitativo na participação das mulheres em posições de liderança não assegura que as condições 
de trabalho, barreiras e preconceitos tenham sido superados nos últimos anos, reforçando a necessidade de dados qualitativos complementares. Estudiosas sobre gênero e esporte alertam que o foco exclusivo no aumento quantitativo de meninas e mulheres no esporte não garante mudanças nos discursos e nas estruturas prevalentes (AITCHISON, 2005; SHAW;FRISBY, 2006). Por fim, lembramos que as projeções realizadas a partir da regressão linear são baseadas em dados retrospectivos de apenas sete anos que correspondem ao total de edições realizadas até o momento. Essa informação é importante para ponderar as estimativas, reconhecer os possíveis vieses da análise e atualizar os dados dessa projeção a cada ano.

\section{CONCLUSÃO}

Se meninas e mulheres conquistaram espaço como praticantes de futebol, o momento atual é de luta por uma maior representatividade nos cargos de liderança. Baseados nos resultados deste estudo, podemos concluir que os homens ocupam predominantemente $(85 \%)$ os cargos de comissão técnica no Campeonato de Brasileiro de Futebol Feminino. A maior inserção das mulheres (22\%) foi encontrada no cargo de auxiliar técnica. Se não houver rupturas no processo de aumento linear e gradual na participação das profissionais nos próximos anos, é possível que a igualdade numérica entre homens e mulheres em cargos de comissão técnica seja alcançada a partir do ano de 2030. As mulheres apresentam uma maior inserção e uma relativa estabilidade no cargo de árbitra assistente (59\%). Apesar da posição de árbitro principal ser majoritariamente ocupada por homens, encontramos uma participação crescente das mulheres nesse cargo. Verificamos uma baixa participação das mulheres como quarta árbitra (22\%) e uma diminuição dessa participação ao longo das edições. É importante que, além da conquista do espaço, essas posições também ofereçam às mulheres reconhecimento profissional e equidade salarial. Esse processo pode ser catalisado por projetos e programas voltados para a capacitação e empoderamento dessas profissionais que promovam rupturas na atual estrutura de poder na sociedade que reproduzem a hierarquia de gênero.

\section{REFERÊNCIAS}

ACOSTA, Vivian; CARPENTER, Linda Jean. Women in Intercollegiate Sport: A Longitudinal, National Study. Thirty-Five Year Update, 1977-2012. New York: Smith College's Project on Women and Social Change and Brooklyn College, 2012.

AITCHISON, Cara Carmichael. Feminist and gender research in sport and leisure management: Understanding the social-cultural nexus of gender-power relations. Journal of Sport Management, v. 19, n. 4, p. 422-441, 2005.

BARREIRA, Júlia et al. Produção acadêmica em futebol e futsal feminino: estado da arte dos artigos científicos nacionais na área da educação física. Movimento, v. 24, n. 2, p. 607618, 2018. 
BRASIL, Conselho Nacional de Desportos. Deliberação n. 7, de 2 de agosto de 1965. Baixa instruções às entidades desportivas do país sobre a prática de desporto. Diário Oficial da União: seção 1, Brasília, DF, p. 8984. Disponível em: https://www.jusbrasil.com. br/diarios/2962672/pg-33-secao-1-diario-oficial-da-uniao-dou-de-02-09-1965. Acesso em: 18jul.2020.

BURTON, Laura J. Underrepresentation of women in sport leadership: A review of research. Sport management review, v. 18, n. 2, p. 155-165, 2015.

CALHEIRO, Ineildes; OLIVEIRA, Eduardo David. Interseccionalidade no esporte: reflexões sobre o estudo com as árbitras de futebol e o método corpo-experiência. Rebeh-Revista Brasileira de Estudos da Homocultura, v. 1, n. 03, p. 34-57, 2018.

CALHEIRO, Ineildes. As mulheres árbitras de futebol: tecnologias de gênero e divisão sexual do trabalho. Rigã: Novas Edições Acadêmicas, 2017.

COHEN, Jacob. Statistical Power Analysis for the Behavioral Sciences. $2^{\text {nd. }}$ ed. Hillsdale: Erlbaum, 1988.

DAMO, Arlei. Do dom à profissão: uma etnografia do futebol de espetáculo a partir da formação de jogadores no Brasil e na França. 2005. Tese (Doutorado em Antropologia Social) - Universidade Federal do Rio Grande do Sul, Porto Alegre, 2005.

EAGLY, Alice; CARLI, Linda. Women and the Labyrinth of Leadership. Harvard Business Review, v. 85, n. 09, p. 63-71, 2007.

FASTING, Kari; SAND, Trond Svela; NORDSTRAND, Hilde Rørvik. One of the few: the experiences of female elite-level coaches in Norwegian football. Soccer \& Society, v. 20, n. 3, p. 454-470, 2019.

FERREIRA, Heidi Jancer et al. A baixa representatividade de mulheres como técnicas esportivas no Brasil. Movimento, v. 19, n. 3, p. 103-124, 2013.

FERREIRA, Heidi Jancer; SALLES, José Geraldo Carmo; MOURÃO, Ludmila Nunes. Inserção e permanência de mulheres como treinadoras esportivas no Brasil. Journal of Physical Education, v. 26, n. 1, p. 21-29, 2015.

FERREIRA, Heidi Jancer et al. Barriers faced by Brazilian female coaches. Revista Brasileira de Educação Física e Esporte, v. 31, n. 2, p. 479-488, 2017.

FORBES, Alison; EDWARDS, Lisa; FLEMING, Scott. 'Women can't referee': exploring the experiences of female football officials within UK football culture. Soccer \& Society, v. 16, n. 4, p. 521-539, 2015.

GOELLNER, Silvana Vilodre. Mulher e esporte no brasil: entre incentivos e interdições elas fazem história. Pensar a Prática, v. 8, n. 1. p. 85-100, 2005.

GOELLNER, Silvana Vilodre. Feminismos, mulheres e esportes: questões epistemológicas sobre o fazer historiográfico. Movimento, v. 13, n. 2, p. 171-196, maio/ago. 2007.

GOMES, Euza. A participação das mulheres na gestão do esporte brasileiro: desafios e perspectivas. Rio de Janeiro: Quartet/FAPERJ, 2008.

HARGREAVES, Jennifer. Sporting females: critical issues in the history and sociology of women's sports. London: Routledge. 1994.

HONG, Fan; MANGAN, James-Antony. Soccer, women, sexual liberation: kicking off a new era. Londres: Routledge, 2003. 
KANE, Mary Jo; STANGL, Jane Marie. Employment patterns of female coaches in men's athletics: Tokenism and marginalization as reflections of occupational sex-segregation.

Journal of Sport and Social Issues, v. 15, n. 1, p. 21-41, 1991.

KANTER, Rosabeth Moss. Men and women of the corporation. New York: Basic books, 1993.

KILTY, Katie. Women in coaching. The Sport Psychologist, v. 20, n. 2, p. 222-234, 2006.

MONTEIRO, Igor Chagas; SOARES, João Paulo Fernandes; MOURÃO, Ludmila. Saindo da "posição de impedimento": As árbitras brasileiras no futebol profissional. In: CONGRESSO BRASILEIRO DE CIÊNCIAS DO ESPORTE (CONBRACE). 19,. 2015. Anais [...] Vitória: CBCE, 2015. Disponível em: http://congressos.cbce.org.br/index.php/conbrace2015/6conice/ paper/viewFile/6875/3636 Acesso em: 18 jul. 2020.

MONTEIRO, Igor Chagas. Mulheres de preto: trajetórias na arbitragem do futebol profissional. 2016. Dissertação (Mestrado em Educação Física e Desportos) - Universidade Federal de Juiz de Fora, 2016.

NORMAN, Leanne. Bearing the Burden of Doubt. Research Quarterly for Exercise and Sport, v. 81, n. 4, p.506-517, 2010a.

NORMAN, Leanne. Feeling second best: Elite women coaches' experiences. Sociology of Sport Journal, v. 27, n. 1, p. 89-104, 2010 b.

NOVAIS, Mariana Cristina Borges. "À beira do gramado ou fora do jogo?": As treinadoras do futebol de mulheres no Brasil. 2018. Dissertação ( Mestrado em Educação Física e Desportos) - Universidade Federal de Juiz de Fora, Juiz de Fora, 2018.

NOVAIS, Mariana Cristina Borges; MOURÃO, Ludmila Nunes; SOARES, João Paulo Fernandes. A dona da bola: questões de gênero na trajetória de uma treinadora de futebol. In: SEMINÁRIO INTERNACIONAL FAZENDO GÊNERO, 11., WOMEN'S WORLDS CONGRESS, 13th., 2017, Florianópolis. Anais [...] Florianópolis: UFSC, 2017. Disponível em: http://www.en.wwc2017.eventos.dype.com.br/resources/anais/1499426042_ARQUIVO TextoFinalFG2017MarianaNovais.pdf Acesso em: 18 jul. 2020.

PASSERO, Julia Gravena et al. Gender (in) equality: a longitudinal analysis of women's participation in coaching and referee positions in the Brazilian Women's Basketball League (2010-2017). Cuadernos de Psicología del Deporte, v.19, n.1, p.252-261, 2019.

PFISTER, Gertrud. Women in sport-gender relations and future perspectives. Sport in Society, v. 13, n. 2, p. 234-248, 2010.

READE, lan; RODGERS, Wendy; NORMAN, Leanne. The under-representation of women in coaching: A comparison of male and female Canadian coaches at low and high levels of coaching. International Journal of Sports Science \& Coaching, v. 4, n. 4, p. 505-520, 2009.

ROMARIZ, Sandra Bellas. As representações de gênero nas quadras de voleibol de alto rendimento. In: FAZENDO GÊNERO, 8., 2008, Florianópolis. Anais [...] Florianópolis: UFSC, 2008. Disponível em: http://www.fazendogenero.eventos.dype.com.br/conteudo/view?ID CONTEUDO=605 Acesso em: 18 jul. 2020.

SARTORE, Melanie; CUNNINGHAM, George. Explaining the under-representation of women in leadership positions of sport organizations: A symbolic interactionist perspective. Quest, v. 59, n. 2, p. 244-265, 2007.

SCHUMAHER, Maria Aparecida. Dicionário mulheres do Brasil: de 1500 até a atualidade. Biográfico e ilustrado. Rio de Janeiro: Zahar, 2000. 
SHAW, Sally; FRISBY, Wendy. Can gender equity be more equitable?: Promoting an alternative frame for sport management research, education, and practice. Journal of Sport Management, v. 20, n. 4, p. 483-509, 2006.

SILVA, Giovana Capucim. Mulheres impedidas: A proibição do futebol feminino na imprensa de São Paulo. Rio de Janeiro: Drible de Letra, 2017.

SOARES, Thereza Amélia. Mulheres em ciência e tecnologia: ascensão limitada. Química Nova, v. 24, n. 2, p. 281-285, 2001.

TEIXEIRA, Fábio Luís Santos; OLIVEIRA CAMINHA, Iraquitan de. Preconceito no futebol feminino brasileiro: uma revisão sistemática. Movimento, v. 19, n. 1, p. 265-287, 2013.

THEBERGE, Nancy. The construction of gender in sport: Women, coaching, and the naturalization of difference. Social Problems, v. 40, n. 3, p. 301-313, 1993.

TORGA, Monique. Com a palavra, as gestoras: A trajetória de mulheres em cargos de gestão no futebol brasileiro. 2019. Dissertação (Mmestrado em Educação Física e Desportos) - Universidade Federal de Juiz de Fora, Juiz de Fora , 2019.

WALKER, Nefertiti; BOPP, Trevor. The underrepresentation of women in the male-dominated sport workplace: Perspectives of female coaches. Journal of Workplace Rights, v. 15, n. 1, p.47-64, 2011.

WOLF, Evelyn. De jogadoras a treinadoras: mulheres rompendo o teto de vidro. 2017. Trabalho de Conclusão (Curso para bacharel em Educação Física) - Universidade Federal do Rio Grande do Sul, Porto Alegre, 2017. 
Abstract: This study analyzes female participation in coaching and referee positions in the Brazilian Women's Football Championship since its first edition in 2013 until 2019. We analyzed the number of women coaches, assistant coaches, physical trainers, massage therapists, goalkeeper coaches, physiotherapists, and doctors. We also collected data about referees. We found male predominance $(\sim 86 \%)$ in coaching positions with a slow increase in the number of women over the years. Female presence seemed to be higher in referee positions. We found $39 \%$ of women working as referees and $59 \%$ as assistant referees. We noted that their participation in coaching and referee positions in the Brazilian Women's Football Championship has been slowly increasing in recent years, but gender inequality remains in leadership and visibility positions.

Keywords: Professional staff committees. Gender Equality. Soccer.

Resumen: El objetivo de este estudio fue analizar la participación de las mujeres en los cargos de comisión técnica y arbitraje en el Campeonato Brasileño de Fútbol Femenino desde su primera edición, en 2013, hasta el año 2019. Analizamos el número de mujeres que actúan como entrenadoras, auxiliares técnicas, preparadoras físicas, masajistas, entrenadoras de porteras, fisioterapeutas y médicas. También recopilamos informaciones sobre el cuarteto de arbitraje. Encontramos un predominio $(\sim 86 \%)$ de hombres en cargos de comisión técnica, con un lento aumento de la participación de mujeres. Las mujeres parecen tener mayor inserción en los cargos de comisión de arbitraje. Encontramos un 39\% de mujeres que actúan como árbitras principales y un $59 \%$ como árbitras asistentes. Constatamos que la participación de mujeres en los cargos de comisión técnica y arbitraje en el Campeonato Brasileño de Fútbol Femenino ha aumentado lentamente en los últimos años, pero que la situación aún es de desigualdad en lo que se refiere a la ocupación de posiciones de liderazgo y visibilidad.

Palabras clave: Comité de profesionales. Igualdad de Género. Fútbol. 


\section{LICENÇA DE USO}

Este é um artigo publicado em acesso aberto (Open Access) sob a licença Creative Commons atribuição Não Comercial 4.0 (CC BY-NC 4.0), que permite uso, distribuição e reprodução em qualquer meio, desde que o trabalho original seja corretamente citado, com a restrição que impede o uso para fins comerciais. Mais informações em: http://creativecommons.org/licenses/by-nc/4.0

\section{CONFLITO DE INTERESSES}

Os autores declararam que não há conflito de interesses neste trabalho.

\section{CONTRIBUIÇÕES DE AUTORIA}

Julia Gravena Passero: Participou da definição do projeto de pesquisa, da coleta dos dados, do tratamento dos dados, discussão dos resultados e escrita do manuscrito.

Júlia Barreira: Participou da definição do projeto de pesquisa, do tratamento dos dados, discussão dos resultados e escrita do manuscrito.

Lucas Tamashiro: Participou da definição do projeto de pesquisa, da coleta dos dados, tratamento dos dados, discussão dos resultados e escrita do manuscrito.

Alcides José Scaglia: Participou da definição do projeto de pesquisa, da discussão dos resultados e escrita do manuscrito.

Larissa Rafaela Galatti: Participou da definição do projeto de pesquisa, da discussão dos resultados e escrita do manuscrito.

\section{FINANCIAMENTO}

Este trabalho não contou com qualquer tipo de financiamento.

\section{COMITÊ/DECLARAÇÃO DE ÉTICA EM PESQUISA}

Não se aplica

\section{COMO REFERENCIAR}

PASSERO, Julia Gravena; BARREIRA, Júlia; TAMASHIRO, Lucas; SCAGLIA, Alcides José; GALATTI, Larissa Rafaela. Futebol de Mulheres Liderado por Homens: uma análise Longitudinal dos Cargos de Comissão Técnica e Arbitragem. Movimento, v. 26, e26060, 2020. Disponível em: https://seer.ufrgs. br/Movimento/article/view/100575. Acessado em: 15 ago. 2020. DOI: https://doi. org/10.22456/1982-8918.100575

\section{RESPONSÁVEIS EDITORIAIS}

Alex Branco Fraga*, Elisandro Schultz Wittizorecki*, Ivone Job*, Mauro Myskiw*, Raquel da Silveira*

*Universidade Federal do Rio Grande do Sul, Escola de Educação Física, Fisioterapia e Dança, Porto Alegre, RS, Brasil 